\title{
Two-level cervical disc replacement: perspectives and patient selection
}

This article was published in the following Dove Press journal:

Open Access Surgery

9 February 2017

Number of times this article has been viewed

\section{Ankur S Narain \\ Fady Y Hijji \\ Daniel D Bohl \\ Kelly H Yom \\ Krishna T Kudaravalli \\ Kern Singh}

Department of Orthopedic Surgery, Rush University Medical Center, Chicago, IL, USA
Correspondence: Kern Singh Department of Orthopedic Surgery, Rush University Medical Center, 161 I W. Harrison St, Suite \#300, Chicago, IL $606 / 2$, USA

$\mathrm{Tel}+\mathrm{I} 3124322373$

Fax +l 7084095179

Email kern.singh@rushortho.com
Introduction: Cervical disc replacement (CDR) is an emerging treatment option for cervical degenerative disease. Postulated benefits of cervical disc replacement compared to anterior cervical discectomy and fusion include preserved motion at the operative segments and decreased motion at adjacent levels. Multiple studies have been performed investigating the outcomes of CDR in single-level pathology. The investigation of the use of CDR in two-level pathology is an emerging topic within the literature.

Purpose: To critically evaluate the literature regarding two-level CDR in order to determine its utility compared to two-level cervical arthrodesis. Patient selection factors including indications and contraindications will also be explored.

Methods: The PubMed database was searched for all articles published on the subject of twolevel CDR up until October 2016. Studies were classified by publication year, study design, sample size, follow-up interval, and conflict of interest. Outcomes were recorded from each study, and included data on patient-reported outcomes, radiographic measurements, range of motion, peri- and postoperative complications, heterotopic ossification, adjacent segment disease, reoperation rate, and total intervention cost.

Results: Fourteen studies were included in this review. All studies demonstrated at least noninferiority of two-level CDR compared to both two-level arthrodesis and single-level CDR. Patient selection in two-level CDR is driven by the inclusion and exclusion criteria presented in prospective, randomized controlled trials. The most common indication is subaxial degenerative disc disease over two contiguous levels presenting with radiculopathy or myelopathy. Furthermore, costs analyses trended toward at least noninferiority of two-level CDR.

Conclusion: Two-level CDR is noninferior to two-level anterior cervical discectomy and fusion in terms of both outcomes and costs. While a few studies suggested superiority of two-level $\mathrm{CDR}$, the presence of significant conflicts of interest by the study authors may introduce bias. Further prospective, randomized trials without conflicts of interest are necessary to determine if two-level CDR demonstrates truly superior outcomes.

Keywords: cervical disc replacement, anterior cervical discectomy and fusion, two-level, patient selection, outcomes, conflict of interest

\section{Introduction}

Anterior cervical discectomy and fusion (ACDF) is a common treatment option for those with symptomatic cervical disc disease. ${ }^{1-4}$ Despite high success rates following ACDF, the risks for pseudarthrosis and adjacent segment disease have raised questions regarding its role as the first-line surgical treatment for cervical degenerative disease. ${ }^{5-9}$ The fusion of cervical vertebrae is thought to reduce motion at the operated level, increasing stress on adjacent cervical disc levels. ${ }^{10}$ Cervical disc replacement 
(CDR) has been proposed as an alternative treatment with the presumed benefit of preserving motion. ${ }^{7-9}$ This theoretical advantage with CDR reduces concern for adjacent segment disease caused by altered biomechanics with ACDF. ${ }^{11}$

The differences in efficacy between CDR and ACDF have been difficult to elucidate. With the prospect of receiving US Food and Drug Administration (FDA) product approval, multiple, large, multicenter, randomized controlled trials have been performed comparing clinical outcomes between these two procedures. ${ }^{10,12,13}$ Results of these studies and others have ranged from noninferiority to superiority of CDR compared to ACDF. ${ }^{8,14}$ Additionally, recent meta-analyses have suggested potential superiority of CDR to ACDF in terms of clinical outcomes. ${ }^{8,11}$ However, these comparative studies have predominately focused on single-level procedures.

Many cervical disc prostheses are FDA-approved for both single-level and two-level CDR. ${ }^{15,16}$ As such, recent efforts have been made to expand the literature to assess the efficacy of two-level CDR. ${ }^{16,17}$ However, similar to single-level CDR, comparative analyses of two-level CDR to ACDF have been inconclusive with regard to clinical outcomes. As such, the purpose of this review article is to summarize the current literature pertaining to the biomechanics, clinical outcomes, and adverse events associated with two-level CDR in order to better describe its efficacy.

\section{Materials and methods}

A literature search was performed using the PubMed search engine to identify all articles published through October 1st, 2016. The search strategy to identify publications assessing two-level CDR in PubMed was " $((($ cervical disc arthroplasty) OR cervical disc replacement) OR disc replacement) OR total disc replacement) AND two level." Only studies with full-text availability that were published in English were included in this review.

Studies that were classified as biomechanical series, clinical case series, retrospective cohort studies, nonrandomized prospective cohort studies, and prospective randomized controlled trials were included in this review. Studies that were single case reports were excluded. All prospective randomized controlled trials, prospective nonrandomized cohort trials, retrospective cohort series, clinical case series, and biomechanical series were assessed for completeness. All studies were then classified by level of evidence, based on criteria established by Sackett et al. ${ }^{18}$ Included studies were also evaluated for conflicts of interest (COI) through review of disclosure sections. The North American Spine Society (NASS) guidelines were utilized to identify any activities as a potential COI.
All included studies were then stratified into cadaveric biomechanical studies, studies assessing clinical benefit, studies assessing adverse events, or studies assessing costs. Clinical outcomes included patient-reported outcomes, radiographic measurements, and range of motion. Adverse events included perioperative complications, heterotopic ossification (HO), and adjacent segment disease (ASD).

\section{Results}

\section{Literature search}

Fourteen studies were included in this review, including five biomechanical studies, four randomized controlled trials, one cost-analysis of a randomized controlled trial, two prospective cohort studies, and two retrospective studies. These studies encompassed 1,360 patients undergoing either CDR or cervical fusion. Summaries of the included studies are presented in Tables 1 and 2.

\section{Cadaveric and biomechanical studies}

In order to better understand the biomechanical properties of two-level CDR, a number of studies involving cadaveric cervical spine specimens have been performed. ${ }^{19-23}$ With regard to range of motion (ROM), the first comparison of two-level CDR to two-level ACDF was performed by Cho et al. ${ }^{20}$ The authors compared ROM in flexion/extension (FE), axial rotation (AR), and lateral bending (LB) in seven C3-T2 cervical spine specimens. Compared to the intact spine with no intervention, two-level ACDF demonstrated significantly decreased C4-T1 ROM in FE, AR, and LB, while two-level arthroplasty demonstrated significantly increased ROM in FE and AR. Two-level fusion constructs also exhibited substantially decreased ROM at the operative level in addition to increased ROM at both superior and inferior adjacent levels. In a study involving 12 cervical spine specimens, Barrey et $\mathrm{al}^{19}$ demonstrated similar findings of decreased ROM in FE, LB, and AR for two-level arthrodesis compared to twolevel CDR. The authors further quantified the ROM increase in adjacent segments in two-level arthrodesis, indicating a $20 \%-38.5 \%$ increase at the superior level and a $25 \%-47 \%$ increase at the inferior level. Expanding on this data, Gandhi et $\mathrm{al}^{21}$ quantified the magnitude of force necessary to produce the observed ROM in 11 cadaveric cervical spines. The authors determined that the least force was required to produce the observed ROM in two-level CDR constructs, while two-level ACDF constructs required twice the applied force to produce the observed ROM in all directions tested.

Intradiscal pressure (IDP) has also been tested in cadaveric specimens as a proxy for the potential for degenerative 
Table I Summary of biomechanical studies

\begin{tabular}{|c|c|c|c|c|c|}
\hline Study & Year & Design $^{a}$ & Sample size (n) & Conflict of interest & Primary result \\
\hline Phillips et $\mathrm{a}^{23}$ & 2009 & $\begin{array}{l}\text { Intact spine } \\
\text { Single-level CDR } \\
\text { Two-level CDR }\end{array}$ & 6 & Yes - industry sponsored & $\begin{array}{l}\text { Two-level CDR provides near-normal mobility; no } \\
\text { destabilization of adjacent segments }\end{array}$ \\
\hline Cho et $\mathrm{al}^{20}$ & 2010 & $\begin{array}{l}\text { Intact spine } \\
\text { Two-level CDR } \\
\text { Two-level ACDF } \\
\text { Hybrid }\end{array}$ & 7 & No & $\begin{array}{l}\text { Two-level ACDF decreases C4-TI ROM and increases } \\
\text { adjacent level ROM } \\
\text { Two-level CDR increases C4-TI ROM; no change in } \\
\text { adjacent level ROM }\end{array}$ \\
\hline Barrey et al ${ }^{19}$ & 2012 & $\begin{array}{l}\text { Intact spine } \\
\text { Single and two level } \\
\text { CDR } \\
\text { Hybrid } \\
\text { Single and two level } \\
\text { ACDF }\end{array}$ & 12 & $\begin{array}{l}\text { Yes - industry sponsored; } \\
\text { consultant fees }\end{array}$ & $\begin{array}{l}\text { Two-level ACDF decreases ROM; increases ROM of } \\
\text { adjacent levels; increased intradiscal pressure } \\
\text { Two-level CDR decreases intradiscal pressure }\end{array}$ \\
\hline Park et a $\left.\right|^{22}$ & 2014 & $\begin{array}{l}\text { Two-level CDR } \\
\text { Hybrid } \\
\text { Two-level ACDF }\end{array}$ & 22 & No & $\begin{array}{l}\text { Distal adjacent level intradiscal pressure decreased in } \\
\text { single- and two-level CDR } \\
\text { Facet contact force approximated in hybrid and two- } \\
\text { level CDR }\end{array}$ \\
\hline Gandhi et $\mathrm{a}^{21}$ & 2015 & $\begin{array}{l}\text { Intact spine } \\
\text { Single- and two- } \\
\text { level CDR } \\
\text { Hybrid } \\
\text { Two-level ACDF }\end{array}$ & 11 & No & $\begin{array}{l}\text { Two-level CDR resulted in increased operative level } \\
\text { motion; least force required for ROM } \\
\text { Two-level ACDF resulted in decreased operative level } \\
\text { ROM and increased adjacent segment ROM; most force } \\
\text { required for ROM }\end{array}$ \\
\hline
\end{tabular}

Notes: aRefers to constructs biomechanically analyzed on cadaver cervical spine specimens. bHybrid indicates hybrid arthroplasty-fusion constructs implanted over two contiguous cervical levels.

Abbreviations: CDR, cervical disc replacement; ACDF, anterior cervical discectomy and fusion; ROM, range of motion.

spinal changes at adjacent levels. Barrey et a ${ }^{19}$ demonstrated that IDPs at the superior adjacent level were significantly different among constructs, with two-level fusion having elevated IDPs and two-level arthroplasty having decreased IDPs compared to the baseline intact spine. The most extensive investigation regarding IDPs was performed by Park et $\mathrm{al}^{22}$ in a study of 22 cervical spine samples. The authors measured IDP in anterior, central, and posterior portions of the intervertebral discs at both the superior and inferior adjacent levels. They determined that central IDP at the proximal adjacent level increased in two-level fusion compared to two-level arthroplasty. Furthermore, they illustrated that anterior IDP in the distal adjacent segment increased during flexion in two-level fusion compared to unchanged values in two-level arthroplasty constructs.

\section{Clinical and radiographic postoperative outcomes}

The evaluation of two-level CDR in terms of clinical and radiographic postoperative outcomes has become an area of interest within the literature. The most thoroughly studied topic has been a comparison of two-level CDR to two-level cervical fusion. In a prospective cohort study, Kim et $\mathrm{al}^{24}$ compared 12 patients receiving two-level CDR with Bryan artificial discs (Medtronic, Memphis, TN, USA) to 28 patients receiving two-level ACDF. At a mean follow-up of 19 months, both groups had significant improvement in VAS and NDI scores from preoperative to final postoperative time points. No difference in improvement was noted between the groups. Furthermore, upon extensive radiographic analysis of these patients, statistically significant differences in ROM, intervertebral heights, and overall sagittal alignment between cohorts were noted. Specifically, compared to preoperative levels, radiographic measures were maintained in the two-level CDR group; however, radiographic measures exhibited significant deviations from preoperative levels in the two-level ACDF group. The authors subsequently concluded that adjacent level degeneration may be less likely in two-level CDR.

Cheng et $\mathrm{al}^{25}$ performed a prospective, randomized controlled trial in which 34 patients received two-level ACDF and 31 patients received two-level CDR with Bryan artificial discs. Similar to the previous study, the authors identified that ROM was maintained in the two-level CDR group but not in the two-level ACDF group. However, in contrast to the previous study, it was demonstrated that two-level CDR had significantly greater improvement in visual analog scale (VAS) neck, VAS arm, Neck Disability Index (NDI), and Short Form 36 (SF-36) scores compared to two-level ACDF at 2 years postoperatively.

In a retrospective case series, Fay et $\mathrm{al}^{26}$ reviewed 37 cases of two-level CDR with Bryan artificial discs and 40 cases of two-level ACDF/ACCF. The authors demonstrated significant improvement in VAS neck, VAS arm, NDI, and Japanese Orthopedic Association (JOA) scores at 24 months 
Table 2 Summary of clinical studies involving two-level CDR

\begin{tabular}{|c|c|c|c|c|c|c|}
\hline Study & Year & Design (LOE $\left.{ }^{a}\right)$ & Sample size (n) & $\begin{array}{l}\text { Follow-up } \\
\text { (months) }\end{array}$ & $\begin{array}{l}\text { Conflict of } \\
\text { interest }\end{array}$ & Primary result \\
\hline Pimenta et $\mathrm{al}^{28}$ & 2007 & $\begin{array}{l}\text { Prospective cohort } \\
\text { (Ila) }\end{array}$ & $\begin{array}{l}71 \text { single-level CDR } \\
69 \text { multi-level CDR } \\
\text { (53 two-level) }\end{array}$ & 36 & $\begin{array}{l}\text { Yes - Industry } \\
\text { supported }\end{array}$ & $\begin{array}{l}\text { Greater improvement in mean NDI, VAS, } \\
\text { Odom's criteria in multilevel cohort at } 3 \text { years } \\
\text { postoperatively }\end{array}$ \\
\hline Kim et $\mathrm{al}^{24}$ & 2009 & $\begin{array}{l}\text { Prospective cohort } \\
\text { (lla) }\end{array}$ & $\begin{array}{l}39 \text { single-level CDR } \\
12 \text { two-level CDR } \\
54 \text { ACDF }(26 \\
\text { single-level, } 28 \\
\text { two-level) }\end{array}$ & 19 & $\mathrm{~N} / \mathrm{A}$ & $\begin{array}{l}\text { Radiographic change } 3.5 \times \text { more likely in ACDF } \\
\text { ROM and intervertebral heights at the operative } \\
\text { site and some adjacent levels maintained in CDR } \\
\text { compared to ACDF }\end{array}$ \\
\hline Cheng et $\mathrm{a}^{25}$ & 2009 & Prospective RCT (lb) & $\begin{array}{l}31 \text { two-level CDR } \\
34 \text { two-level ACDF }\end{array}$ & 24 & $N / A$ & $\begin{array}{l}\text { CDR had greater improvement in PROs } \\
\text { compared to ACDF } \\
\text { ACDF had decreased operative-level ROM }\end{array}$ \\
\hline Cardoso et $\mathrm{a}^{30}$ & 2010 & Retrospective (IV) & $\begin{array}{l}24 \text { multilevel CDR } \\
\text { (10 two-level) }\end{array}$ & 12 & No & $\begin{array}{l}\text { No noted complications at } 12 \text { months } \\
\text { postoperatively }\end{array}$ \\
\hline Huppert et $\mathrm{a}^{29}$ & 2011 & Prospective RCT (lb) & $\begin{array}{l}\text { I75 single-level } \\
\text { CDR } \\
56 \text { Multi-level CDR } \\
\text { (5I two-level) }\end{array}$ & 24 & $\begin{array}{l}\text { Yes - Industry } \\
\text { sponsored }\end{array}$ & $\begin{array}{l}\text { No difference in PRO improvement between } \\
\text { cohorts } \\
\text { No difference in complication/reoperation rate } \\
\text { between cohorts } \\
\text { ROM improvement was statistically equivalent } \\
\text { between cohorts }\end{array}$ \\
\hline Fay et $\mathrm{a}^{26}$ & 2014 & Retrospective (IV) & $\begin{array}{l}37 \text { two-level CDR } \\
40 \text { two-level ACDF } \\
\text { or ACCF }\end{array}$ & 24 & No & $\begin{array}{l}\text { No difference in PRO improvement between } \\
\text { cohorts } \\
\text { No difference in complications/reoperation rate } \\
\text { between cohorts } \\
\text { CDR cohort had increased ROM; Fusion cohort } \\
\text { had decreased ROM }\end{array}$ \\
\hline Bae et $\mathrm{al}^{17}$ & 2015 & Prospective RCT (lb) & $\begin{array}{l}\text { I64 single-level } \\
\text { CDR } \\
225 \text { two-level CDR }\end{array}$ & 48 & No & $\begin{array}{l}\text { No differences in PRO improvement or } \\
\text { satisfaction between cohorts } \\
\text { Rates of HO not different between cohorts } \\
\text { No differences in complications or reoperation } \\
\text { rate between cohorts }\end{array}$ \\
\hline Davis et $\mathrm{al}^{27}$ & 2015 & Prospective RCT (lb) & $\begin{array}{l}225 \text { two-level CDR } \\
\text { I04 two-level } \\
\text { ACDF }\end{array}$ & 48 & $\begin{array}{l}\text { Yes - industry } \\
\text { sponsored }\end{array}$ & $\begin{array}{l}\text { CDR group showed greater improvement in } \\
\text { PROs and patient satisfaction rates } \\
\text { Rate of ASD lower in CDR cohort } \\
\text { Rate of reoperation lower in CDR cohort }\end{array}$ \\
\hline Ament et a $\left.\right|^{32}$ & 2016 & $\begin{array}{l}\text { Cost-Analysis of } \\
\text { Prospective RCT (lb) }\end{array}$ & 330 (Davis et $\mathrm{al}^{27}$ ) & 60 & $\begin{array}{l}\text { Yes - industry } \\
\text { sponsored }\end{array}$ & $\begin{array}{l}\text { Two-level CDR group had significant costs } \\
\text { savings compared to Two-level ACDF }\end{array}$ \\
\hline
\end{tabular}

Notes: a $L$ evel evidenced determined via criteria from Sackett et al. ${ }^{18}$

Abbreviations: LOE, level of evidence; CDR, cervical disc replacement; RCT, randomized controlled trial; ACDF, anterior cervical discectomy and fusion; ACCF, anterior cervical corpectomy and fusion; NDI, Neck Disability Index; VAS, visual analog scale; ROM, range of motion; PRO, patient-reported outcomes; HO, heterotopic ossification; ASD, adjacent segment degeneration.

postoperatively in both groups, with no statistically significant difference between cohorts. Similar to the previously mentioned studies, radiographic analysis indicated that two-level fusion led to significantly decreased range of motion at the operative level compared to two-level CDR.

The most recent and largest study was a prospective, randomized US Food and Drug Administration (FDA) investigational device exemption (IDE) trial conducted by Davis et al. ${ }^{27}$ This study included 4-year follow-up data for 225 patients undergoing two-level CDR (Mobi-C, LDR Medical, Troyes, France) and 105 control patients undergoing two-level ACDF. Both two-level CDR and two-level ACDF groups exhibited significant improvement in NDI, VAS, and Short Form 12
(SF-12) physical (PCS) and SF-12 mental composite scores (MCS) at 4-years postoperatively. However, improvement in NDI and SF-12 PCS was determined to be significantly greater in the two-level CDR cohort. Furthermore, when queried regarding patient satisfaction, patients who received two-level CDR had significantly higher satisfaction rates and would be more likely to recommend their intervention to a friend.

Another topic of study has been the comparison of outcomes between patients with single-level pathology receiving single-level CDR and patients with two-level pathology receiving two-level CDR procedures. Pimenta et $\mathrm{a}^{28}$ conducted the first prospective cohort study comparing single- and multilevel CDR, in which 71 patients receiving 
single-level and 69 patients receiving multilevel CDR (Porous Coated Motion Device Dynamic Intervertebral Disc Spacer, Cervitech, Rockaway, NJ, USA) were compared. The authors demonstrated that the multilevel cohort had significantly greater improvements in mean NDI, mean VAS, and Odom's criteria at 3-year follow-up compared to the single-level cohort. Huppert et a ${ }^{29}$ compared 56 patients undergoing $\geq$ twolevel CDR (Mobi-C) to 175 patients undergoing single-level CDR in a prospective, multicenter study. At 2-year follow-up, both groups had statistically significant improvements in NDI, arm VAS, neck VAS, and SF-36 scores. No statistical difference was noted between the groups. On radiographic analysis, the majority of operative segments in both cohorts had improved ROM with no difference between the two groups. Postoperatively, $\geq$ two-level CDR patients were noted to consume more analgesics and trended toward later return-to-work compared to single-level CDR. Bae et a ${ }^{17}$ also demonstrated statistically equivalent PRO improvement between cohorts in a prospective IDE trial comparing 164 patients receiving single-level CDR to 225 patients receiving two-level CDR (Mobi-C). Furthermore, upon extensive radiographic analysis, both single- and two-level CDR cohorts maintained operative level ROM in FE and LB at 4 years postoperatively.

\section{Adverse events, adjacent segment disease, and reoperation rate}

Determination of the complication rate of two-level CDR has been an important outcome in many of the previously mentioned studies. In terms of total adverse events (AEs), multiple studies have identified a low rate of AEs coupled with no difference in $\mathrm{AE}$ rate between two-level CDR and either two-level cervical fusion or single-level CDR. ${ }^{17,26-30}$ Multiple retrospective case series have reported no significant AEs after 12-24 months postoperatively in patients undergoing two-level CDR. ${ }^{26,30}$ Huppert et a ${ }^{29}$ determined that while the incidence of total adverse events did not differ between groups undergoing two-level or single-level CDR, the incidence of dysphagia was significantly higher in patients undergoing multilevel surgery. However, all cases of dysphagia were self-limited and did not require further intervention. Similarly, Bae et al ${ }^{17}$ demonstrated no statistically significant difference in complication rate between single-level CDR (4.3\%) and two-level CDR (4.0\%) at 24 months postoperatively. Comparing complication rates between two-level CDR and two-level ACDF, Davis et al ${ }^{27}$ noted rates of $4.0 \%$ in CDR versus $7.6 \%$ in ACDF; however, this difference was also not statistically significant.

Of the measured complications, radiographic adjacent segment degeneration and symptomatic ASD have been topics of interest due to their association with reoperation requirement. Fay et $\mathrm{al}^{26}$ noted no occurrence of symptomatic ASD in their population of two-level CDR and two-level ACDF patients. However, the authors stated that follow-up longer than 24 months may be required for accurate assessment of ASD. Davis et $\mathrm{al}^{27}$ noted a higher rate of adjacent segment degeneration for two-level ACDF (85.9\%) than for two-level CDR (41.5\%). The reported rate of reoperation in two-level CDR patients among all included studies ranged from $0.0 \%-4.0 \%{ }^{17,26,27,29}$ All studies supported at least noninferiority of two-level CDR, with Davis et $\mathrm{al}^{27}$ being the only study to support a decreased rate of reoperation compared to two-level ACDF (4.0\% versus $8.6 \%$ ).

Finally, heterotopic ossification (HO) is considered one of the major complications associated with cervical disc replacement procedures. As such, comparisons of the rate of $\mathrm{HO}$ in patients undergoing $\mathrm{CDR}$ at single- or two-levels have been included in various studies. Of the studies included in this review, those analyzing HO have shown the rate to be equivalent or lower in two-level CDR compared to single-level CDR. ${ }^{17,29}$ Huppert et al ${ }^{29}$ radiographically categorized cases of $\mathrm{HO}$ from grade I to grade $\mathrm{V}$ at 24 months postoperatively, and it was determined that single-level CDR had an increased risk of higher grade $\mathrm{HO}$ compared to two-level CDR. However, no comparison of overall rate of $\mathrm{HO}$ between single-level and two-level CDR was presented.

\section{Costs}

In the current health care climate, data regarding costs of particular interventions are becoming increasingly utilized to shape management decisions. While previous studies have demonstrated reduced long-term costs after single-level CDR compared to single-level ACDF, only recently has cost data become available for two-level CDR procedures. ${ }^{31}$ Ament et $\mathrm{a}^{32}$ performed a series of cost analyses of the data from the FDA IDE study conducted by Davis et al. ${ }^{27}$ The authors demonstrated that two-level CDR was "dominant" compared to two-level ACDF at 5-year follow-up. The incremental costeffective ratio (ICER) for two-level CDR was $-\$ 165,103$ per quality adjusted life year (QALY) from a societal perspective. A negative ICER value is, by convention, associated with costs savings. Furthermore, two-level CDR was associated with a $\$ 32,690$ costs savings over the first five postoperative years compared to two-level ACDF.

\section{Discussion}

Cervical disc replacement represents an alternative to ACDF for the treatment of cervical degenerative disease. The postulated benefits of CDR include increased cervical mobility and 
decreased incidence of ASD. While the majority of published literature involves the characterization of single-level CDR, recent studies have been performed with the intent to characterize the efficacy and safety of two-level CDR. The purpose of this review was to summarize the major biomechanical and clinical publications regarding two-level CDR and to better describe its relative efficacy compared to cervical fusion.

The present review suggests that two-level CDR is noninferior to two-level cervical fusion in the treatment of cervical degenerative disease. Of the analyzed studies that included information regarding patient-reported outcomes (NDI, VAS, SF-12, etc.) and postoperative complications, all of them demonstrated at minimum no significant differences between $\mathrm{CDR}$ and $\mathrm{ACDF}^{24-27}$ Conclusions are mixed between studies regarding the superiority versus noninferiority of CDR. This may possibly stem from the use of different postoperative outcome measures and differing follow-up intervals. Radiographically, the majority of presented studies demonstrated that operative site ROM was increased compared to preoperative and adjacent segment ROM approximated preoperative levels in two-level CDR cases. This contrasted the results of two-level ACDF, in which operative site ROM was decreased and adjacent level ROM was increased. Based on previous biomechanical studies performed by Durbhakula et $\mathrm{al}^{33}$ and Dmitriev et al, ${ }^{5}$ this pattern suggests that the risk of ASD is decreased in two-level CDR compared to two-level cervical fusion. However, no study involving two-level CDR has correlated the incidence of radiographically-identified adjacent segment degeneration with clinically symptomatic ASD requiring reoperation. Thus, while two-level ACDF may be associated with greater radiographic adjacent segment degeneration compared to two-level CDR, the rate of clinically relevant ASD may not differ.

The results of this review also suggest noninferiority of two-level CDR for two-level pathology compared to single-level CDR procedures for single-level pathology. The majority of conducted prospective studies have demonstrated that no statistical difference exists in terms of clinical, biomechanical, or radiographic outcomes between single-level and two-level CDR cohorts. ${ }^{17,28,29}$ This suggests that practitioners and patients can expect similar postoperative improvements in patients with multilevel disease who undergo CDR compared to those with single-level pathology. As only three studies have been performed that directly assess outcomes comparing single- and two-level populations, further investigation is necessary to make any definitive conclusions.

Analyzing potential conflicts of interest is necessary, especially in studies utilizing and comparing industry-produced medical devices. Of the studies included in this review, six were identified as having conflicts of interest related to the receipt of financial support or assistance with study conduct by the company producing the artificial disc implant. ${ }^{19,23,27-29}$ The presence of these conflicts may inherently bias these studies toward producing at least noninferior, if not superior, comparative results. In the general orthopedic literature, Okike et $a l^{34}$ demonstrated that studies with conflicts of interest involving royalties, stock options, consulting fees, or employee status were more likely to report positive findings. Similarly, in a study of 1,356 spinal journal articles, Amiri et $a \mathrm{l}^{35}$ determined that industry financed studies exhibited higher rates of favorable outcomes and lower overall level of evidence. Further research comparing the results of conflicted and nonconflicted CDR studies would be beneficial in definitively determining if bias exists in industry-sponsored CDR research.

Patient selection in two-level CDR is necessarily driven by the various inclusion and exclusion criteria presented in prospective, randomized controlled trials. The most common indications include subaxial, degenerative disc disease over two contiguous levels presenting with myelopathy or radiculopathy. ${ }^{17,24,26,29}$ Furthermore, patients must have failed a trial of conservative therapy spanning a minimum of 6-8 weeks. Typical contraindications include osteoporosis, metabolic bone disease, malignancy, and infection. Additionally, within the population of patients with two-level cervical degenerative disc disease, it has been recommended that CDR be contraindicated in those with insufficient motion or bridging osteophytes at one or more of the index levels. ${ }^{36}$ In such cases, alternative therapy in the form of fusionarthroplasty hybrid constructs has been proposed. While cadaveric studies have indicated that hybrid constructs have decreased adjacent segment motion, ${ }^{21,22}$ there is a paucity of clinical studies assessing outcomes after utilization of hybrid constructs in comparison to two-level fusion. Further prospective, randomized studies are required to fully delineate the potential efficacy of hybrid constructs in cases where CDR is contraindicated.

In the current health care climate, cost-utility exhibits an important role in patient selection and the utilization of two-level CDR versus two-level ACDF. Recently published long-term costs analyses support reduced costs in both single-level and two-level CDR compared to single-level and two-level fusion, respectively. ${ }^{31,32}$ As previously mentioned, Ament et $\mathrm{al}^{32}$ utilized data from the FDA IDE study conducted by Davis et $\mathrm{al}^{27}$ to demonstrate that two-level CDR was associated with significant cost savings compared to two-level ACDF. However, the results of this study must be analyzed in the context that the source data comes from an 
industry-sponsored clinical trial. As such, there is the possibility of bias influencing both data collection and analysis. This suggests a necessity for further costs analyses of twolevel CDR clinical trials not involving any potential conflicts of interest. Nonetheless, the current trend in cost analyses supports that two-level CDR should not be eliminated as a potential treatment option for qualifying patients.

This review is not without limitations. First, the inclusion of studies with conflicts of interest may hinder the ability to make definitive conclusions from this review. However, these studies represent a significant portion of the literature regarding CDR, and it was determined that exclusion of these investigations would detract from providing the most comprehensive summary of the topic. Second, the included biomechanical and clinical studies utilized artificial cervical discs from differing manufacturers. Third, the included clinical studies had differing lengths of required follow-up, limiting the ability to rigorously compare those studies. Fourth, a similar limitation exists in that the presented studies utilized differing types of patient-reported and clinical outcome measures. Finally, the strategy for detecting and classifying $\mathrm{HO}$ and adjacent segment disease differed between studies. Thus, accurate comparisons of rates of those complications are limited. While these limitations may hinder the comparative ability of this review, they are not unique issues and are common among all reviews of prospective or retrospective studies.

\section{Conclusion}

The current literature suggests that two-level CDR is noninferior to two-level cervical fusion in the treatment of multilevel cervical degenerative disc disease. While a portion of the published literature supports the superiority of two-level CDR in terms of both outcomes and costs, the relative paucity of studies without significant conflicts of interest impedes the ability to make a definitive assessment. Patient selection criteria are driven by the methodology of published clinical trials and include an indication of cervical degenerative disease at two contiguous levels with resulting radiculopathy or myelopathy. Furthermore, alternative therapies such as hybrid fusion-arthroplasty are emerging as potential therapeutic strategies in this patient population. Further prospective, nonconflicted, randomized trials are necessary to better determine the efficacy and safety of two-level CDR.

\section{Disclosure}

No funds were received in support of this work. No benefits in any form have been or will be received from any commercial party related directly or indirectly to the subject of this manuscript. The authors report no other conflicts of interest in this work.

\section{References}

1. Chang H, Baek DH, Choi BW. The relationship between increased intervertebral disc height and development of postoperative axial neck pain after anterior cervical fusion. J Korean Neurosurg Soc. 2014;55: 343-347.

2. Hessler C, Boysen K, Regelsberger J, Vettorazzi E, Winkler D, Westphal M. Patient satisfaction after anterior cervical discectomy and fusion is primarily driven by relieving pain. Clin J Pain. 2012;28:398-403.

3. Peolsson A. Investigation of clinically important benefit of anterior cervical decompression and fusion. Eur Spine J. 2007;16:507-514.

4. Zigler JE, Rogers RW, Ohnmeiss DD. Comparison of 1-level versus 2-level anterior cervical discectomy and fusion: clinical and radiographic follow-up at 60 months. Spine (Phila Pa 1976). 2016;41:463-469.

5. Dmitriev AE, Cunningham BW, Hu N, Sell G, Vigna F, McAfee PC. Adjacent level intradiscal pressure and segmental kinematics following a cervical total disc arthroplasty: an in vitro human cadaveric model. Spine (Phila Pa 1976). 2005;30:1165-1172.

6. Eck JC, Humphreys SC, Lim TH, et al. Biomechanical study on the effect of cervical spine fusion on adjacent-level intradiscal pressure and segmental motion. Spine. 2002;27:2431-2434.

7. Boselie TF, Willems PC, van Mameren H, de Bie RA, Benzel EC, van Santbrink H. Arthroplasty versus fusion in single-level cervical degenerative disc disease: a Cochrane review. Spine. 2013;38:E1096-E1107.

8. McAfee PC, Reah C, Gilder K, Eisermann L, Cunningham B. A metaanalysis of comparative outcomes following cervical arthroplasty or anterior cervical fusion: results from 4 prospective multicenter randomized clinical trials and up to 1226 patients. Spine. 2012;37:943-952.

9. Sasso RC, Anderson PA, Riew KD, Heller JG. Results of cervical arthroplasty compared with anterior discectomy and fusion: four-year clinical outcomes in a prospective, randomized controlled trial. Orthopedics. 2011;34:889.

10. Mummaneni PV, Burkus JK, Haid RW, Traynelis VC, Zdeblick TA. Clinical and radiographic analysis of cervical disc arthroplasty compared with allograft fusion: a randomized controlled clinical trial. J Neurosurg Spine. 2007;6:198-209.

11. Gao Y, Liu M, Li T, Huang F, Tang T, Xiang Z. A meta-analysis comparing the results of cervical disc arthroplasty with anterior cervical discectomy and fusion (ACDF) for the treatment of symptomatic cervical disc disease. J Bone Joint Surg Am. 2013;95:555-561.

12. Heller JG, Sasso RC, Papadopoulos SM, et al. Comparison of BRYAN cervical disc arthroplasty with anterior cervical decompression and fusion: clinical and radiographic results of a randomized, controlled, clinical trial. Spine (Phila Pa 1976). 2009;34:101-107.

13. Murrey D, Janssen M, Delamarter R, et al. Results of the prospective, randomized, controlled multicenter Food and Drug Administration investigational device exemption study of the ProDisc-C total disc replacement versus anterior discectomy and fusion for the treatment of 1-level symptomatic cervical disc disease. Spine J. 2009;9:275-286.

14. Bartels RH, Donk R, Verbeek AL. No justification for cervical disk prostheses in clinical practice: a meta-analysis of randomized controlled trials. Neurosurgery. 2010;66:1153-1160; discussion 60.

15. Wu JC, Huang WC, Tsai HW, et al. Differences between 1- and 2-level cervical arthroplasty: more heterotopic ossification in 2-level disc replacement: Clinical article. J Neurosurg Spine. 2012;16:594-600.

16. Alvin MD, Mroz TE. The Mobi-C cervical disc for one-level and twolevel cervical disc replacement: a review of the literature. Med Devices (Auckl). 2014;7:397-403.

17. Bae HW, Kim KD, Nunley PD, et al. Comparison of clinical outcomes of 1- and 2-level total disc replacement: four-year results from a prospective, randomized, controlled, multicenter IDE clinical trial. Spine (Phila Pa 1976). 2015;40:759-766.

18. Sackett DL, Strauss SE, Richardson WS, Rosenberg W, Haynes R. Evidence-Based Medicine: How to Practice and Teach EBM. 2nd ed. New York, NY: Churchill Livington; 2000. 
19. Barrey C, Campana S, Persohn S, Perrin G, Skalli W. Cervical disc prosthesis versus arthrodesis using one-level, hybrid and two-level constructs: an in vitro investigation. Eur Spine J. 2012;21:432-442.

20. Cho BY, Lim J, Sim HB, Park J. Biomechanical analysis of the range of motion after placement of a two-level cervical ProDisc-C versus hybrid construct. Spine (Phila Pa 1976). 2010;35:1769-1776.

21. Gandhi AA, Kode S, DeVries NA, Grosland NM, Smucker JD, Fredericks DC. Biomechanical analysis of cervical disc replacement and fusion using single level, two level, and hybrid constructs. Spine (Phila Pa 1976). 2015;40:1578-1585.

22. Park J, Shin JJ, Lim J. Biomechanical analysis of disc pressure and facet contact force after simulated two-level cervical surgeries (fusion and arthroplasty) and hybrid surgery. World Neurosurg. 2014;82:1388-1393.

23. Phillips FM, Tzermiadianos MN, Voronov LI, et al. Effect of two-level total disc replacement on cervical spine kinematics. Spine (Phila Pa 1976). 2009;34:E794-E799.

24. Kim SW, Limson MA, Kim SB, et al. Comparison of radiographic changes after ACDF versus Bryan disc arthroplasty in single and bilevel cases. Eur Spine J. 2009;18:218-231.

25. Cheng L, Nie L, Zhang L, Hou Y. Fusion versus Bryan Cervical Disc in two-level cervical disc disease: a prospective, randomised study. Int Orthop. 2009;33:1347-1351.

26. Fay LY, Huang WC, Tsai TY, et al. Differences between arthroplasty and anterior cervical fusion in two-level cervical degenerative disc disease. Eur Spine J. 2014;23:627-634.

27. Davis RJ, Nunley PD, Kim KD, et al. Two-level total disc replacement with Mobi-C cervical artificial disc versus anterior discectomy and fusion: a prospective, randomized, controlled multicenter clinical trial with 4-year follow-up results. J Neurosurg Spine. 2015;22:15-25.
28. Pimenta L, McAfee PC, Cappuccino A, Cunningham BW, Diaz R, Coutinho E. Superiority of multilevel cervical arthroplasty outcomes versus single-level outcomes: 229 consecutive PCM prostheses. Spine (Phila Pa 1976). 2007;32:1337-1344.

29. Huppert J, Beaurain J, Steib JP, et al. Comparison between single- and multi-level patients: clinical and radiological outcomes 2 years after cervical disc replacement. Eur Spine J. 2011;20:1417-1426.

30. Cardoso MJ, Rosner MK. Multilevel cervical arthroplasty with artificial disc replacement. Neurosurg Focus. 2010;28:E19.

31. McAnany SJ, Overley S, Baird EO, et al. The 5-year cost-effectiveness of anterior cervical discectomy and fusion and cervical disc replacement: a Markov analysis. Spine (Phila Pa 1976). 2014;39:1924-1933.

32. Ament JD, Yang Z, Nunley P, Stone MB, Lee D, Kim KD. Cost utility analysis of the cervical artificial disc vs fusion for the treatment of 2-level symptomatic degenerative disc disease: 5-Year follow-up. Neurosurgery. 2016;79:135-145.

33. Durbhakula MM, Ghiselli G. Cervical total disc replacement, part I: rationale, biomechanics, and implant types. Orthop Clin North Am. 2005;36:349-354.

34. Okike K, Kocher MS, Mehlman CT, Bhandari M. Conflict of interest in orthopaedic research. An association between findings and funding in scientific presentations. J Bone Joint Surg Am. 2007;89:608-613.

35. Amiri AR, Kanesalingam K, Cro S, Casey AT. Does source of funding and conflict of interest influence the outcome and quality of spinal research? Spine J. 2014;14(2):308-314.

36. Shin DA, Yi S, Yoon DH, Kim KN, Shin HC. Artificial disc replacement combined with fusion versus two-level fusion in cervical two-level disc disease. Spine (Phila Pa 1976). 2009;34:1153-1159; discussion $1160-1161$
Open Access Surgery

\section{Publish your work in this journal}

Open Access Surgery is an international, peer-reviewed, open access journal that focuses on all aspects of surgical procedures and interventions Patient care around the peri-operative period and patient outcomes post surgery are key topics for the journal. All grades of surgery from minor cosmetic interventions to major surgical procedures are covered. Novel techniques and the

\section{Dovepress}

utilization of new instruments and materials, including implants and prostheses that optimize outcomes constitute major areas of interest. The manuscrip management system is completely online and includes a very quick and fair peer-review system, which is all easy to use. Visit http://www.dovepress.com testimonials.php to read real quotes from published authors. 